
\title{
28 Research Suare \\ Levetiracetam induction of theta frequency oscillations in rodent hippocampus in vitro
}

Hang Xing

Xinxiang Medical University

Cheng Biao Lu

XXMU https://orcid.org/0000-0002-8949-7388

Xiong Han ( $\nabla$ hanxiong7589@126.com )

https://orcid.org/0000-0002-3673-1564

Xin'e Xie

Xinxiang Medical University

Yuan Wang

Xinxiang Medical University

\section{Research article}

Keywords: Levetiracetam, theta oscillation, hippocampus, NMDAR, GABAAR, taurine, atropine

Posted Date: August 30th, 2019

DOI: https://doi.org/10.21203/rs.2.13686/v1

License: (c) (1) This work is licensed under a Creative Commons Attribution 4.0 International License. Read Full License

Version of Record: A version of this preprint was published at Canadian Journal of Physiology and Pharmacology on October 1st, 2020. See the published version at https://doi.org/10.1139/cjpp-20190727. 


\section{Abstract}

Background Levetiracetam (LEV), an antiepileptic drug, has been recently demonstrated to improve the cognitive function. Hippocampal theta rhythm $(4-12 \mathrm{~Hz})$ is associated with a variety of cognitively related behaviors, such as exploration, locomotion and spatial memory in both humans and animal models. We investigated the effects of LEV on the theta rhythm in the rat hippocampal CA3 area. Results We found that LEV increased the power of theta oscillation in a dose-dependent manner. The increase in theta power can be blocked by GABAA receptor or NMDA receptor antagonists but not by AMPA receptor antagonist, indicating the involvement of GABAA receptor and NMDA receptor in the induction of theta activity. Interestingly, LEV enhancement of theta power can be also blocked by taurine, indicating that LEV induction of theta may be related to the indirect boosting of GABA action via reduction of extrasynaptic GABAA receptor activation. Furthermore, the increased theta power can be partially reduced by mACh receptor antagonist atropine but not by nACh receptor antagonists, suggesting that mACh receptor activation provides excitatory input into local network responsible for LEV induction of theta. Conclusions Our study demonstrated that induction of a synchronized network oscillation, a novel role of LEV may especially benefit for the treatment of the neuronal disorders with impaired theta oscillation and cognitive function.

\section{Background}

Hippocampal theta rhythm $(4-12 \mathrm{~Hz})$ plays a key role in cognitive processes in both humans and animals $[1,2]$ and is associated with a variety of cognitively related behaviors, including spatial coding, memory and sniffing exploratory locomotion[3]. The decreased theta activity is correlated with cognitive deficit seen in neurodegenerative disease such as epilepsy and Alzheimer's disease $(A D)[4,5,6,7]$.

The pharmacological induction of theta rhythm is determined by local neuronal circuits activated by specific receptor agonists including both metabotropic acetylcholine receptor (mAChR) and nicotinic acetylcholine receptor (nAChR) agonists in hippocampus[8, 9], suggesting that cholinergic neurotransmission play a role in hippocampal theta generation.

Levetiracetam (LEV) is an anti-epileptic drug for the treatment of partial onset and generalized seizures $[10,11]$. Recently, LEV has been demonstrated to improve cognitive impairment of an Alzheimer's disease model [12] and to have a neuroprotective effects on brain injury $[13,14,15]$ at its therapeutic plasma concentration $(35-118 \mu \mathrm{M})[16]$.

Accumulated evidence indicates that LEV improves the impairment in patients with amnestic mild cognitive impairment by reducing the hyperactivity of the hippocampus [17] and spatial memory impairment in a mouse kindling model and rat pilocarpine model of temporal lobe epilepsy(TLE) $[18,19]$. It has also been reported that LEV can improve the memory function defects of a ketamine-induced schizophrenia model [20]. 
$\mathrm{GABA}_{A}$ receptor $\left(G A B A_{A} R\right)$ appears to be critical for pharmacologically induced theta oscillations $[8,9,21$, 22 , 23]. Taurine, rich in the brain, is an inhibitory amino acid, potently activates $G A B A_{A} R$ in rat hippocampal $C A 1$ area and consequently modulates theta via activating $G_{A B A_{A}} R[24,25]$. LEV has been reported to enhance $G A B A_{A} R$ function [26], it is likely LEV modulates theta activity, which maybe affected by taurine, as there were negative effects of LEV on taurine production[27], which could indirectly boost GABA action via extrasynaptic $\mathrm{GABA}_{\mathrm{A}} \mathrm{R}$ activation and increase network activity.

Whether LEV affects theta oscillation has not yet been reported. In this study, we found that LEV dramatically enhanced theta oscillations of the rat hippocampal CA3 area.

\section{Results}

\section{LEV-induced theta oscillations in hippocampal slices}

The basal activity of field potentials were recorded at CA3 area of rat hippocampal slices, perfusion of aCSF for 80 min had no effect on basal activity of field potentials $(n=4$, Fig. 1A-B). The application of LEV $(3-100 \mu \mathrm{M})$ induced persistent theta oscillation $(4-12 \mathrm{~Hz})$ in CA3 area of rat hippocampal slices. Examples of LEV-induced theta oscillation were shown in figure 1C-F. The peak frequency of LEV-induced theta oscillation was $8.1 \pm 1.6 \mathrm{~Hz}$ ( $v s$ control $5.0 \pm 1.3 \mathrm{~Hz}$, paired t-test, $p<0.05, n=6$ ), $9.7 \pm 0.9 \mathrm{~Hz}$ (vs control $5.4 \pm 1.1 \mathrm{~Hz}$, paired t-test, $\mathrm{p}<0.01, \mathrm{n}=6), 8.8 \pm 0.6 \mathrm{~Hz}$ ( vs control $5.4 \pm 1.0 \mathrm{~Hz}$, paired t-test, $\mathrm{p}<0.01, \mathrm{n}=6$ ) and $9.5 \pm 1.6 \mathrm{~Hz}$ ( vs control $5.8 \pm 1.0 \mathrm{~Hz}$, paired t-test, $\mathrm{p}<0.01, \mathrm{n}=11$ ) for $3 \mu \mathrm{M}, 10 \mu \mathrm{M}, 30 \mu \mathrm{M}$ and $100 \mu \mathrm{M}$, respectively(figure 1F). Compared with the control, there was a significant difference in the mean peak frequency after applying LEV and there was no significant difference in the mean peak frequency among the various concentrations of LEV treatments (ANOVA, $p>0.05$ ). The area power of LEV-induced theta oscillation was 9.6 $\pm 1.6 \mu \mathrm{V}^{2}$ (vs control $7.7 \pm 1.2 \mu \mathrm{V}^{2}$ ), $6.9 \pm 1.0 \mu \mathrm{V}^{2}$ (vs control $5.0 \pm 0.8 \mu \mathrm{V}^{2}$ ), $23.9 \pm 9.1 \mu \mathrm{V}^{2}$ ( vs control $15.5 \pm 6.0 \mu \mathrm{V}^{2}$ ) and $24.9 \pm 6.3 \mu \mathrm{V}^{2}$ (vs control $8.0 \pm 1.2 \mu \mathrm{V}^{2}$ ) for $3 \mu \mathrm{M}, 10 \mu \mathrm{M}, 30 \mu \mathrm{M}$ and $100 \mu \mathrm{M}$, respectively. Compared with the control, LEV dose-dependently increased the area power by $23 \%(p>0.05$, $n=6), 44 \%(p>0.05, n=6), 70 \%(p<0.05, n=6)$ and $174 \%(p<0.01, n=11)$ for $3 \mu M, 10 \mu M, 30 \mu M$ and $100 \mu \mathrm{M}$, respectively (ANOVA, post hoc Tukey test, $\mathrm{p}<0.01$, figure $1 \mathrm{G}$ ).

\section{LEV-induced theta oscillations were mediated by NMDA receptors and $\mathrm{GABA}_{\mathrm{A}}$ receptors}

In order to determine the mechanisms of LEV-induced theta oscillation, we examined the effects of the ionotropic glutamate receptor antagonist D-AP5 or NBQX or the ionotropic $\mathrm{GABA}_{A} \mathrm{R}$ antagonist bicuculline on LEV-induced theta oscillation. In a set of experiments $(n=6)$, pretreatment of hippocampal slices with D-AP5 $(50 \mu \mathrm{M})$ had no effect on baseline area power, further application of LEV (100 $\mu \mathrm{M})$ caused a small increase without statistically significant difference (paired t-test, $p>0.05, n=6$, figure $2 A 1-3$ ). In a different set of experiments $(n=8)$, we pretreated slices with NBQX $(20 \mu M)$, further application of LEV 
$(100 \mu \mathrm{M})$ caused a dramatic increase $(383 \pm 111 \%$ vs NBQX $100 \%$, paired t-test, $p<0.01, n=8$, figure 2 B13 ) in area power. Compared with LEV alone, there was no significant difference (Student t-test, $p>0.05$ ). In another set of experiments $(n=6)$, pretreatment of hippocampal slices with bicuculline $(2 \mu M)$ had no effect on baseline area power, further application of LEV $(100 \mu \mathrm{M})$ failed to induce any oscillatory activity (paired t-test, $p>0.05, n=6$, figure $2 \mathrm{C} 1-3$ ). The results therefore indicated that LEV-induced theta oscillation is mediated by both NMDA receptor and $G_{A B A}$ receptor.

\section{Taurine was involved in LEV-induced theta oscillations}

Taurine is an inhibitory amino acid, potently acts on $\mathrm{GABA}_{A}$ receptors located at both synaptic and nonsynaptic sites, is functionally similar to the role of GABA[24]. LEV was reported to significantly reduce taurine level in the hippocampus [27]. To determine whether taurine is involved in LEV-induced theta oscillations, we studied the effects of taurine on LEV-induced oscillation. We pretreated hippocampal slices with taurine $(100 \mu \mathrm{M})$ for $20 \mathrm{~min}$ and further application of LEV $(100 \mu \mathrm{M})$ caused little change on baseline area power $(107 \pm 8.4 \%$ vs taurine $100 \%$, paired t-test, $p>0.05, n=6$, figure 3$)$. The results showed that taurine pretreatment blocked LEV-induced theta oscillations.

\section{mACh receptors but not nACh receptors or L-type $\mathrm{Ca}^{2+}$ channel mediate LEV-induced theta oscillations}

Previous study indicates that, we here determined whether LEV-induced theta oscillations are mediated by mACh receptors. Atropine pretreatment $(50 \mu \mathrm{M})$ had no role on baseline, further application of LEV (100 $\mu \mathrm{M})$ caused a small but significant increase in area power $(150 \pm 13.7 \%$ vs atropine $100 \%$, paired t-test, $p<0.01, n=10$, figure $4 A 1-3)$. There was significant difference in area power between LEV and LEV+atropine (Student t-test, $p<0.05$ ), indicating that LEV-induced theta oscillation was partially blocked by atropine.

Previous study showed that nAChR agonist induced theta oscillation in hippocampus [9], we further determined whether nACh receptors is involved in LEV-induced theta oscillations by using a7 nAChR antagonist MLA $(100 \mathrm{nM})$ and $\mathrm{a} 4 \beta 2 \mathrm{nAChR}$ antagonist DHBE $(0.4 \mu \mathrm{M})$. Pretreatment of a combined MLA and $\mathrm{DH} \beta \mathrm{E}$, had no effect on baseline activity, further application of LEV $(100 \mu \mathrm{M})$ caused a significant increase in area power $(261 \pm 36.9 \%$ vs MLA and DH $\beta E 100 \%$, paired t-test, $\mathrm{p}<0.01, \mathrm{n}=6$, figure $4 \mathrm{~B} 1-3)$. Our results indicated that nACh receptors don't contribute to LEV-induced oscillatory activity.

In another set of experiments $(n=6)$, L-type Ca2+ channel antagonist nifidepine $(10 \mu \mathrm{M})$ was applied to pretreat hippocampal slices, further application of LEV $(100 \mu \mathrm{M})$ caused a significant increase in area power $(221 \pm 38 \%$ vs nifidepine $100 \%$, paired t-test, $p<0.01, n=6$, figure $4 \mathrm{C} 1-3)$. Thus, these results indicate that L-type Ca2+ channel did not involve in the regulation of LEV-induced theta oscillations. 


\section{Discussion}

In this study, we demonstrate that LEV is able to elicit persistent oscillatory activity at theta frequency bands in hippocampal CA3 area, which are mediated by NMDA receptors and GABAA receptors as well as partially by mAChR.

Hippocampal theta rhythm is crucial for spatial memory and is thought to be generated by extrinsic synaptic transmissions. lonotropic glutamatergic receptor agonist kainate or nAChR agonist nicotine can both induce theta oscillation in medial septal diagonal band (MSDB), which was blocked by GABAAR antagonist and was partially blocked by the AMPA/kainate or NMDA receptor (NMDAR) blocker [21, 22]. Carbachol (a mAChR agonist) or nicotine induced theta oscillations in hippocampal CA3 area, which was also blocked by $\mathrm{GABA}_{\mathrm{A}}$ receptor antagonist and was partially blocked by the AMPA/kainate or NMDA receptor blocker $[8,9,23]$. Thus, it appears that these pharmacologically-induced oscillations were reduced by both $\mathrm{GABA}_{A} \mathrm{R}$ and ionotropic glutamate receptor antagonists, indicating the involvement of local GABAergic and glutamatergic neurons in the production of the rhythmic theta activity.

In this study, LEV-induced theta oscillation was also involved in the activation of local $G_{A B A} R$ and NMDAR. Surprisingly, we found that pretreatment with NBQX did not affect LEV-induced theta oscillations, suggesting that AMPA receptor (AMPAR) was not involved in LEV-induction of theta oscillation. This is in agreement with previous findings that $\mathrm{GABA}_{A}$ receptors and inotropic glutamatergic receptors (NMDAR) are critical for the induction of theta oscillation[3]. AMPAR appears to be not involved in LEV induced oscillation, which is sort of similar to the theta oscillation induced by DHPG+ NBQX [28]. In our case, LEV+NBQX appears to induced a higher theta relative to LEV alone, suggesting that in DHPG+NBQX and LEV induced theta did not require AMPAR activation.

LEV had no effect on AMPA-induced glutamate release [29], which may explain that AMPAR was not involved in LEV-induced theta activity. Whereas others reported that LEV reduced the EPSC amplitude via affecting the presynaptic voltage-dependent calcium channel [30]. Thus, we currently have no clear explanation about why LEV-induced theta was not involved in AMPAR. NMDAR involvement of LEVinduced theta may be explained by the observation that LEV increased selectively NMDA-induced glutamate release [29].

LEV specifically binds to synaptic vesicle protein 2A (SV2A), which is widely expressed in different brain regions. Interestingly, SV2A is a only subtype of the SV2 family expressed in GABAergic neurons [31] and is implicated in the control of GABA release [32]. Acute application of LEVreversed the negative allosteric regulation of $\mathrm{Zn}^{2+}$ on the $G A B A_{A} R$ in cultured hippocampal neurons [26]. These studies suggest that LEV may enhance GABA release and $G A B A_{A} R$ function and thus theta oscillation.

Taurine is a potent activator of extrasynaptic $\mathrm{GABA}_{A}$ receptors [33, 34]. Extrasynaptic $G A B A_{A} R$ may downregulate theta oscillation, as extrasynaptic $G_{A B A} R$-mediated tonic inhibition counteracts the excitation of interneurons and down-regulate network oscillations [35]. This may explain taurine blockage of LEV 
induction of theta oscillation. Thus it can infer that LEV may inhibit extrasynaptic $G_{A B} A_{A} R$ activation via reducing taurine level in the hippocampus [27], indirectly boost GABA action and contribute to the theta oscillations.

In this study LEV-induced theta oscillation was partially blocked by atropine but not affected by nAChR antagonist, indicating that $\mathrm{mAChR}$ but not $\mathrm{nAChR}$ was involved in the regulation of LEV-induced theta, although nAChR agonist nicotine induced theta oscillations in hippocampal CA3 area[22]. Our results were supported by the observation that LEV facilitated cholinergic function via mAChR activation [36].

It is likely that LEV may activate G-protein related signaling molecules including mAChR activation and NMDAR, leading to the excitation of GABAergic neurons and GABA release as well as activation of $G A B A_{A}$ receptors within local neuronal network. Thus LEV-induced oscillation in hippocampal CA3 area is mediated by $\mathrm{GABA}_{A} R, \mathrm{NMDAR}$ and $\mathrm{mAChR}$.

Animal model of TLE exhibits a decrease in the power of theta oscillations correlated with spatial memory deficits [37]. LEV can improve the impaired spatial memory in the TLE rats [19], LEV induction of theta oscillation may contribute to the improvement of cognition. Thus our findings provide additional evidence to support clinical application of LEV in the neuropsychological disorders associated with impairment of theta activity.

\section{Conclusions}

In summary, it is the first study to demonstrate that LEV is able to elicit persistent oscillatory activity at theta frequency bands in hippocampal CA3 area, which are mediated by NMDA receptors and GABA $A$ receptors as well as partially by mAChR. LEV may especially benefit for the treatment of the neuronal disorders with impaired theta oscillation and cognitive function.

\section{Materials And Methods Experimental animals}

Adult male Sprague-Dawley rats weighing 100-150 g were used in the current study. The rats were purchased from Zhengzhou University (Zhengzhou, China). All the animals were maintained under a $12 \mathrm{~h} / 12 \mathrm{~h}$ light/dark cycle with a constant room temperature of $23 \pm 1{ }^{\circ} \mathrm{C}$. This study was carried out in accordance with the principles of the Basel Declaration and recommendations of the guidelines for animal experiments, Ethics Committees at Xinxiang Medical University. The protocol was approved by the Ethics Committees at Xinxiang Medical University. Furthermore, this manuscript reporting adheres to the ARRIVE guidelines for the reporting of animal experiments. In addition, we have made every effort to minimize the number of animals used.

\section{Drugs and agents}


(2S)-(2-Oxopyrrolidin-1-yl)butyramide (Levetiracetam), 2-Aminoethylsulfonic acid (taurine)and 1,4Dihydro-2,6-dimethyl-4-(2-nitrophenyl)-3,5-pyridinedicarboxylic acid dimethyl ester (nifedipine)were purchased from Sigma-Aldrich (St Louis, MO, USA); D-(-)-2-Amino-5-phosphonopentanoic acid (D-AP5), 2,3-Dioxo-6-nitro-1,2,3,4-tetrahydrobenzo[f]quinoxaline-7-sulfonamide (NBQX), [R-( $\left.\left.R^{\star}, S^{\star}\right)\right]-6-(5,6,7,8$ Tetrahydro-6-methyl-1,3-dioxolo[4,5-g]isoquinolin-5-yl)furo[3,4-e]-1,3-benzodioxol-8(6H)-one

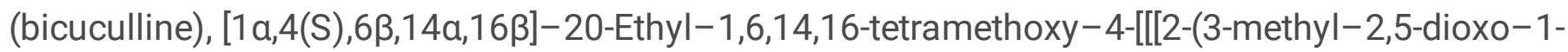
pyrrolidinyl)benzoyl]oxy]methyl]aconitane-7,8-diol citrate (MLA) and (2S,13bS)-2-Methoxy2,3,5,6,8,9,10,13-octahydro-1H,12H-benzo[i]pyrano[3,4-g]indolizin-12-one hydrobromide (DHßE) were purchased from Tocris Bioscience (Bristol, UK); endo-( \pm )-a-(Hydroxymethyl)benzeneacetic acid 8-methyl8-azabicyclo[3.2.1]oct-3-yl ester (atropine) was purchased from MedChemexpress (Monmouth Junction, NJ, USA). All agents were dissolved in water, except nifedipine was dissolved in DMSO.

\section{Preparation of hippocampal slices}

Experimental animals were anaesthetised by by intraperitoneal injection of chloral hydrate $(400 \mathrm{mg} / \mathrm{kg})$. When all pedal reflexes were abolished, the animals underwent intracardiac perfusion with chilled $\left(5^{\circ} \mathrm{C}\right)$, oxygenated artificial cerebrospinal fluid (aCSF) in which the sodium chloride had been replaced by isoosmotic sucrose. This aCSF solution ( $305 \mathrm{mmol} / \mathrm{L}$ ) contained the following (in $\mathrm{mmol} / \mathrm{L}$ ): 225 sucrose, 3 $\mathrm{KCl}, 1.25 \mathrm{NaH}_{2} \mathrm{PO}_{4}, 24 \mathrm{NaHCO}_{3}, 6 \mathrm{MgSO}_{4}, 0.5 \mathrm{CaCl}_{2}$, and 10 glucose. Horizontal hippocampal slices were cut into $400-\mu \mathrm{m}$ sections using a Leica VT1000S vibratome (Leica Microsystems UK, Milton Keynes, UK). The slices were then transferred to an incubation chamber, where they remained submerged in oxygenated aCSF, which consisted of (in mmol/L) $126 \mathrm{NaCl}, 3 \mathrm{KCl}, 1.25 \mathrm{NaH}_{2} \mathrm{PO}_{4}, 2 \mathrm{MgSO}_{4}, 24 \mathrm{NaHCO}_{3}$, $2 \mathrm{CaCl}_{2}$, and 10 glucose, $\mathrm{pH} 7.35-7.45$ at room temperature until used for recording.

\section{Field potential recording}

For local field potential (LFP) recordings, slices were placed a recording chamber at the interface between aCSF $(2-3 \mathrm{ml} / \mathrm{min})$ at $32{ }^{\circ} \mathrm{C}$ and warm moist carbogen that maintained a thin film of aCSF covering the slice to ensure applied substances could diffuse into the area recorded. LFP were recorded from

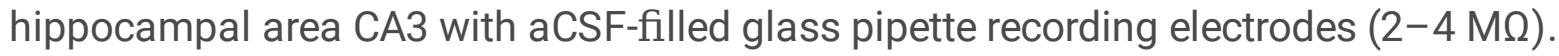

Field potentials were amplified with Neurolog NL106 AC-coupled amplifiers (Digitimer, Welwyn Garden City, UK) and band-pass filtered at 2-200 Hz with Neurolog NL125 filters (Digitimer). After mains line noise was removed with Humbug noise eliminators (Digitimer), the signal was digitized and sampled at 2 kHz using a CED-1401 Plus (Cambridge Electronic Design, Cambridge, UK) and Spike-2 software (Cambridge Electronic Design).

Data were analyzed off-line using software from Spike 2 (CED, Cambridge, UK). Power spectra were generated to provide a quantitative measure of the frequency components in a stretch of recording, where power, a quantitative measure of the oscillation strength, was plotted against the respective frequency. 
Power spectra were constructed for $60 \mathrm{~s}$ epochs of field potential recordings $(1 \mathrm{~Hz}$ bin size, Hanning window, FFT size 2048) using a fast Fourier transform algorithm provided by Spike2. The parameters used for measuring the oscillatory activity in the slice were peak frequency $(\mathrm{Hz})$ and area power $(\mu \mathrm{V} 2)$. In the current study, area power was equivalent to the computed area under the power spectrum between the frequencies of 4 and $14 \mathrm{~Hz}[38]$. All statistical tests were performed using SPSS (SPSS Inc, USA).

\section{Statistical analysis}

All data are expressed as mean \pm standard error of mean (SEM) or medians \pm min-max for non-normally distributed data. Statistical significance for comparison between two groups was performed using a student $t$-test if data appeared to be normally distributed or a Wilcoxon signed-rank test if the data were not normally distributed (nonparametric data). Multiple comparisons among groups were analyzed using one-way repeated measures Analysis of Variance (ANOVA, post hoc Tukey test). If $P<0.05$, the treatments were considered to have a statistically significant difference.

\section{Abbreviations}

AMPAR AMPA receptor

LEV Levetiracetam

mAChR metabotropic acetylcholine receptor

nAChR nicotinic acetylcholine receptor

NMDAR NMDA receptor

TLE temporal lobe epilepsy

GABAAR GABAA receptor

SV2A synaptic vesicle protein $2 \mathrm{~A}$

\section{Declarations}

\section{Ethics approval and consent to participate}

This study was carried out in accordance with the principles of the Basel Declaration and recommendations of the guidelines for animal experiments, Ethics Committees at Xinxiang Medical University. The protocol was approved by the Ethics Committees at Xinxiang Medical University.

\section{Consent for publication}


Not applicable.

\section{Availability of data and material}

The datasets of this study are available from the corresponding author on request.

\section{Competing interests}

The authors declare that they have no competing interests.

\section{Funding}

This study was supported by the Science foundation and frontier technology research project of Henan province, China (grant no 152300410155) and National Natural science foundation of China (grant no 81771517).

\section{Authors' contributions}

Study design: CBL and XH. Study conduct: HX, XEX and YW. Data collection: HX, XEX and YW. Data analysis: $\mathrm{HX}$ and CBL. Data interpretation: $\mathrm{HX}$ and $\mathrm{CBL}$. Drafting manuscript: $\mathrm{HX}$ and CBL. Revising manuscript: $\mathrm{CBL}, \mathrm{XH}$ and $\mathrm{HX}$. All authors read and approved the final manuscript.

\section{Acknowledgments}

Not applicable.

\section{References}

1.Belchior $\mathrm{H}$, Lopes-Dos-Santos $\mathrm{V}$, Tort AB, Ribeiro S: Increase in hippocampal theta oscillations during spatial decision making. Hippocampus 2014, 24(6):693-702.

2.Kahana MJ, Sekuler R, Caplan JB, Kirschen M, Madsen JR: Human theta oscillations exhibit task dependence during virtual maze navigation. Nature 1999, 399(6738):781-784.

3.Buzsaki G: Theta oscillations in the hippocampus. Neuron 2002, 33(3):325-340.

4.Hu MM, Yan XD, Zhang XM, Bai Y, Zhao F, Qi JS: [Application of wireless neuronal recording system in fear conditioning of Alzheimer's disease mice - hippocampal Theta oscillation observation]. Sheng li xue bao: [Acta physiologica Sinica] 2018, 70(5):571-578. 
5.Kilias A, Haussler U, Heining K, Froriep UP, Haas CA, Egert U: Theta frequency decreases throughout the hippocampal formation in a focal epilepsy model. Hippocampus 2018, 28(6):375-391.

6.Ge ML, Guo JD, Chen SH, Zhang JC, Fu XX, Chen YM: [Quantitative evaluation of inhibitory effects of epileptic spikes on theta rhythms in the network of hippocampal CA3 and entorhinal cortex in patients with temporal lobe epilepsy]. Sheng li xue bao: [Acta physiologica Sinica] 2017, 69(1):77-88.

7.Li X, Hou Y, Ren Y, Tian X, Song Y: Alterations of theta oscillation in executive control in temporal lobe epilepsy patients. Epilepsy research 2018, 140:148-154.

8.Konopacki J, Maclver MB, Bland BH, Roth SH: Carbachol-induced EEG 'theta' activity in hippocampal brain slices. Brain research 1987, 405(1):196-198.

9.Lu CB, Henderson Z: Nicotine induction of theta frequency oscillations in rodent hippocampus in vitro. Neuroscience 2010, 166(1):84-93.

10.Schiemann-Delgado J, Yang H, Loge Cde L, Stalvey TJ, Jones J, Legoff D, Mintz M: A long-term openlabel extension study assessing cognition and behavior, tolerability, safety, and efficacy of adjunctive levetiracetam in children aged 4 to 16 years with partial-onset seizures. Journal of child neurology 2012, 27(1):80-89.

11.De Smedt T, Raedt R, Vonck K, Boon P: Levetiracetam: part II, the clinical profile of a novel anticonvulsant drug. CNS drug reviews 2007, 13(1):57-78.

12.Sanchez PE, Zhu L, Verret L, Vossel KA, Orr AG, Cirrito JR, Devidze N, Ho K, Yu GQ, Palop JJ et al: Levetiracetam suppresses neuronal network dysfunction and reverses synaptic and cognitive deficits in an Alzheimer's disease model. Proceedings of the National Academy of Sciences of the United States of America 2012, 109(42):E2895-2903.

13.Browning M, Shear DA, Bramlett HM, Dixon CE, Mondello S, Schmid KE, Poloyac SM, Dietrich WD, Hayes RL, Wang KK et al: Levetiracetam Treatment in Traumatic Brain Injury: Operation Brain Trauma Therapy. Journal of neurotrauma 2016, 33(6):581-594.

14.Zou H, Brayer SW, Hurwitz M, Niyonkuru C, Fowler LE, Wagner AK: Neuroprotective, neuroplastic, and neurobehavioral effects of daily treatment with levetiracetam in experimental traumatic brain injury. Neurorehabilitation and neural repair 2013, 27(9):878-888.

15.Wang H, Gao J, Lassiter TF, McDonagh DL, Sheng H, Warner DS, Lynch JR, Laskowitz DT: Levetiracetam is neuroprotective in murine models of closed head injury and subarachnoid hemorrhage. Neurocritical care 2006, 5(1):71-78.

16.West PJ, Saunders GW, Remigio GJ, Wilcox KS, White HS: Antiseizure drugs differentially modulate $\theta$ burst induced long-term potentiation in C57BL/6 mice. Epilepsia 2014, 55(2):214-223. 
17.Bakker A, Krauss GL, Albert MS, Speck CL, Jones LR, Stark CE, Yassa MA, Bassett SS, Shelton AL, Gallagher M: Reduction of hippocampal hyperactivity improves cognition in amnestic mild cognitive impairment: Neuron. 2012 May 10;74(3):467-74. doi:10.1016/j.neuron.2012.03.023.; 2012.

18.Barker-Haliski ML, Vanegas F, Mau MJ, Underwood TK, White HS: Acute cognitive impact of antiseizure drugs in naive rodents and corneal-kindled mice. Epilepsia 2016, 57(9):1386-1397.

19.Ge YX, Tian XZ, Lin YY, Liu XY: Chronic treatment with levetiracetam reverses deficits in hippocampal LTP in vivo in experimental temporal lobe epilepsy rats. Neuroscience letters 2016, 628:194-200.

20.Koh MT, Shao Y, Rosenzweig-Lipson S, Gallagher M: Treatment with levetiracetam improves cognition in a ketamine rat model of schizophrenia. Schizophrenia research 2017.

21.Garner HL, Whittington MA, Henderson Z: Induction by kainate of theta frequency rhythmic activity in the rat medial septum-diagonal band complex in vitro. The Journal of physiology 2005, 564(Pt 1):83102.

22. Lu CB, Li CZ, Li DL, Henderson Z: Nicotine induction of theta frequency oscillations in rodent medial septal diagonal band in vitro. Acta pharmacologica Sinica 2013, 34(6):819-829.

23.Palhalmi J, Paulsen O, Freund TF, Hajos N: Distinct properties of carbachol- and DHPG-induced network oscillations in hippocampal slices. Neuropharmacology 2004, 47(3):381-389.

24.0ja SS, Saransaari P: Significance of Taurine in the Brain. Advances in experimental medicine and biology 2017, 975 Pt 1:89-94.

25.del Olmo N, Bustamante J, del Rio RM, Solis JM: Taurine activates $G A B A(A)$ but not $G A B A(B)$ receptors in rat hippocampal CA1 area. Brain Res 2000, 864(2):298-307.

26.Rigo J, Hans G, Nguyen L, Rocher V, Belachew S, Malgrange B, Leprince P, Moonen G, Selak I, Matagne A et al: The anti-epileptic drug levetiracetam reverses the inhibition by negative allosteric modulators of neuronal GABA- and glycine-gated currents. British Journal of Pharmacology 2002, 136(5):659-672.

27.Tong X, Patsalos PN: A microdialysis study of the novel antiepileptic drug levetiracetam: extracellular pharmacokinetics and effect on taurine in rat brain. Br J Pharmacol 2001, 133(6):867-874.

28.Gillies MJ, Traub RD, LeBeau FE, Davies CH, Gloveli T, Buhl EH, Whittington MA: A model of atropineresistant theta oscillations in rat hippocampal area CA1. The Journal of physiology 2002, 543(Pt 3):779793.

29.Pastukhov A, Borisova T: Levetiracetam-mediated improvement of decreased NMDA-induced glutamate release from nerve terminals during hypothermia. Brain research 2018, 1699:69-78. 
30.Lee CY, Chen CC, Liou HH: Levetiracetam inhibits glutamate transmission through presynaptic P/Qtype calcium channels on the granule cells of the dentate gyrus. British Journal of Pharmacology 2009, 158(7):1753-1762.

31.Bajjalieh SM, Frantz GD, Weimann JM, McConnell SK, Scheller RH: Differential expression of synaptic vesicle protein 2 (SV2) isoforms. The Journal of neuroscience: the official journal of the Society for Neuroscience 1994, 14(9):5223-5235.

32.Crowder KM, Gunther JM, Jones TA, Hale BD, Zhang HZ, Peterson MR, Scheller RH, Chavkin C, Bajjalieh SM: Abnormal neurotransmission in mice lacking synaptic vesicle protein $2 A$ (SV2A). Proceedings of the National Academy of Sciences of the United States of America 1999, 96(26):15268.

33.Furukawa T, Yamada J, Akita T, Matsushima Y, Yanagawa Y, Fukuda A: Roles of taurine-mediated tonic $G A B A A$ receptor activation in the radial migration of neurons in the fetal mouse cerebral cortex. Frontiers in Cellular Neuroscience 2014, 8:88.

34.Jia F, Yue M, Chandra D, Keramidas A, Goldstein PA, Homanics GE, Harrison NL: Taurine Is a Potent Activator of Extrasynaptic GABA $<s u b>A</$ sub $>$ Receptors in the Thalamus. The Journal of Neuroscience 2008, 28(1):106-115.

35.Brickley SG, Mody l: Extrasynaptic GABA(A) receptors: their function in the CNS and implications for disease. Neuron 2012, 73(1):23-34.

36. Wulfert E, Hanin I, Verloes R: Facilitation of calcium-dependent cholinergic function by ucb L059, a new "second generation" nootropic agent. Psychopharmacology bulletin 1989, 25(3):498-502.

37.Chauviere L, Rafrafi N, Thinus-Blanc C, Bartolomei F, Esclapez M, Bernard C: Early deficits in spatial memory and theta rhythm in experimental temporal lobe epilepsy. The Journal of neuroscience: the official journal of the Society for Neuroscience 2009, 29(17):5402-5410.

38.Csicsvari J, Jamieson B, Wise KD, Buzsaki G: Mechanisms of gamma oscillations in the hippocampus of the behaving rat. Neuron 2003, 37(2):311-322.

\section{Figures}


A

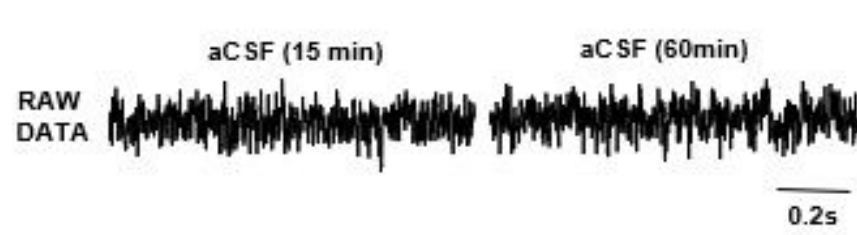

C

CTRL(15min)

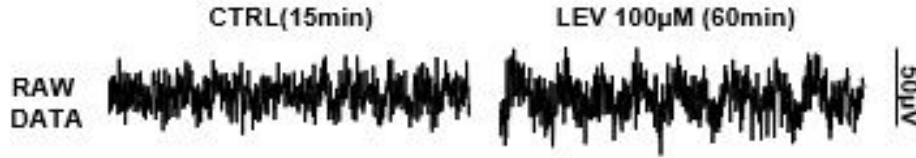

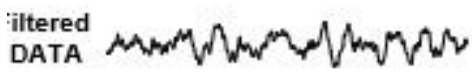

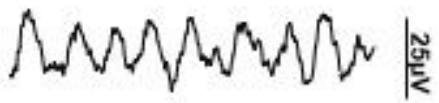

$\overline{0.2 \mathrm{~s}}$

E

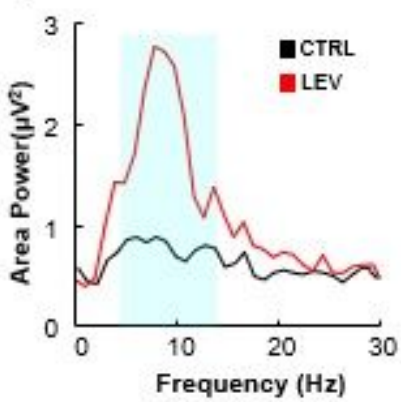

F

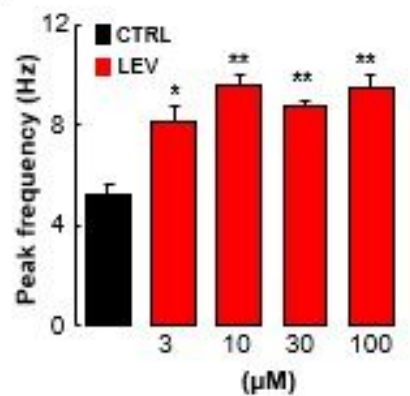

B

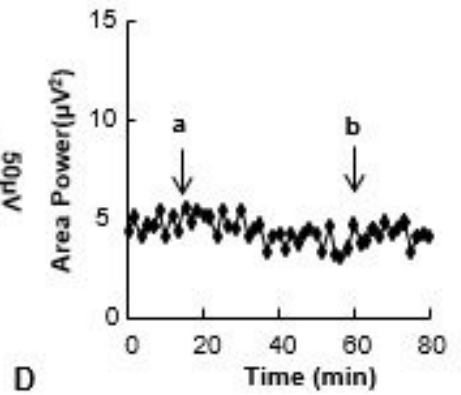

D

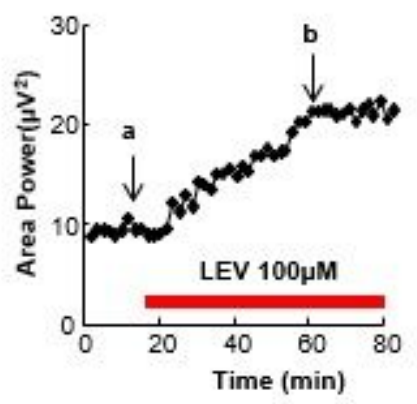

G

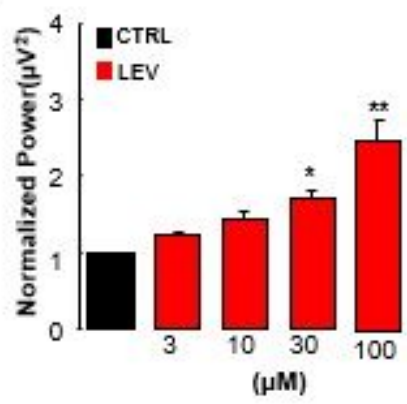

Figure 1

LEV-induced theta oscillations in the CA3 area of rat hippocampal slices. A, Examples of local field potentials recorded in the CA3 area of a hippocampal slice for the control at 15min (a) and 60 min (b) perfusion of aCSF. B, The time-effect curve for area power of the theta oscillation ( theta power) under aCSF perfusion. C, Examples of local field potentials recorded in the CA3 area of a hippocampal slice for the control (15min, a) and the presence of $100 \mu \mathrm{M} \mathrm{LEV} \mathrm{(60} \mathrm{min,} \mathrm{b).} \mathrm{D,} \mathrm{The} \mathrm{time-effect} \mathrm{curve} \mathrm{for} \mathrm{the} \mathrm{theta}$ power before and after application of LEV $(100 \mu \mathrm{M})$. E, The power spectra of the recordings corresponding to that shown in C. F, The effects of different concentrations of LEV on the peak frequency of oscillations. G, Normalized area powers of LEV-induced theta oscillations for $3 \mu M(n=6), 10 \mu M(n=6)$, $30 \mu \mathrm{M}(\mathrm{n}=6)$ and $100 \mu \mathrm{M}(\mathrm{n}=13)$, respectively. Error bars indicate SEM. * indicates $\mathrm{P}<0.05$, ** indicates $\mathrm{P}$ $<0.01$, in comparison with control, paired t-test or ANOVA with post hoc Tukey test. 
A1

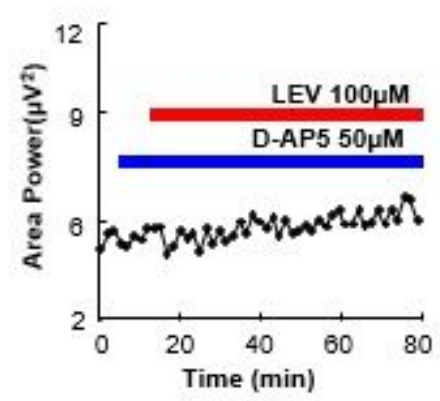

B1
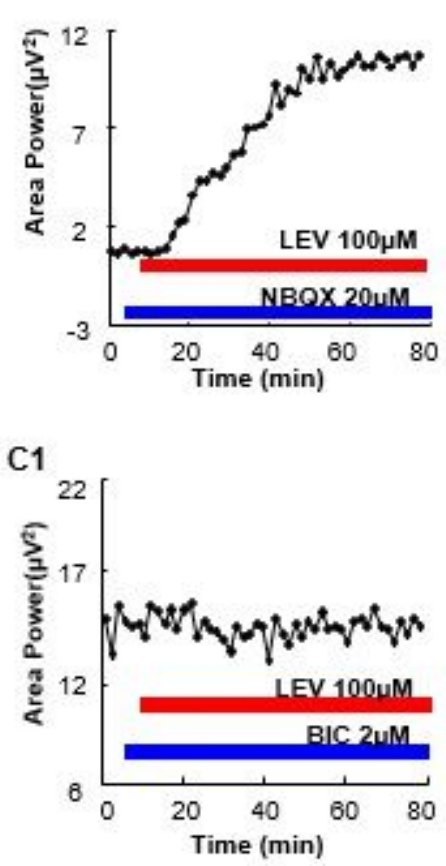

A2

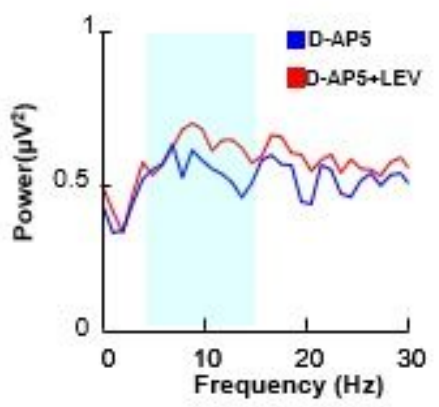

B2

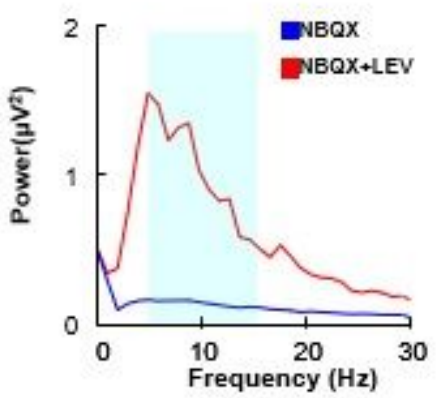

C2

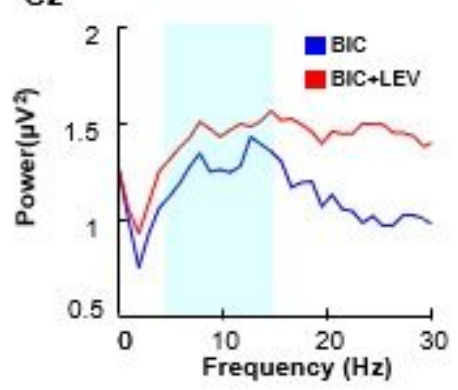

A3

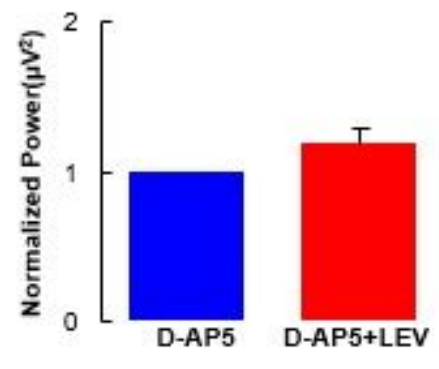

B3
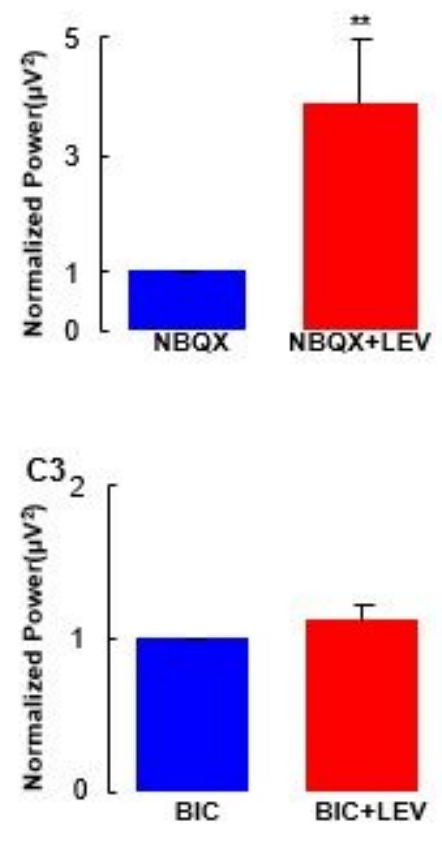

Figure 2

GABAA receptors and NMDA receptors mediate LEV-induced theta oscillations in the hippocampal CA3 area. A1, Time-effect curve for the area power of the oscillations in the application of $50 \mu M$ D-AP5, followed by $100 \mu \mathrm{M}$ LEV. A2, The corresponding power spectra of of the oscillations shown in A1. A3, Bar graph summarized the changes in normalized area power of oscillations for $50 \mu \mathrm{M}$ D-AP5 and DAP5+100 $\mu \mathrm{M} \mathrm{LEV}(n=8)$. B1, Time-effect curve for the area power of the oscillations in the application of $2 \mu \mathrm{M}$ bicuculline, followed by $100 \mu \mathrm{M}$ LEV. B2, The corresponding power spectra of of the oscillations shown in B1. B3, Bar graph summarized the changes in normalized area power of oscillations for $2 \mu \mathrm{M}$ bicuculline and bicuculline+100 $\mu \mathrm{M} \operatorname{LEV}(n=6)$. C1, Time-effect curve for the area power of the oscillations in the application of $20 \mu \mathrm{M}$ NBQX, followed by $100 \mu \mathrm{M}$ LEV. C2, The corresponding power spectra of of the oscillations shown in $\mathrm{C} 1$. C3, Bar graph summarized the changes in normalized area power of oscillations for $20 \mu \mathrm{M} \mathrm{NBQX}$ and NBQX+100 $\mu \mathrm{M} \mathrm{LEV}(\mathrm{n}=8)$. Error bars indicate SEM. * indicates $\mathrm{P}<0.05$, ** indicates $\mathrm{P}<0.01$, in comparison with antagonist, paired t-test. 
A

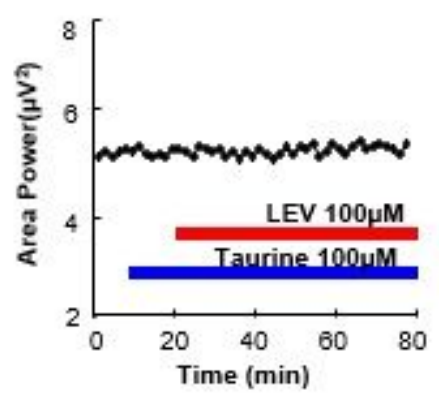

B

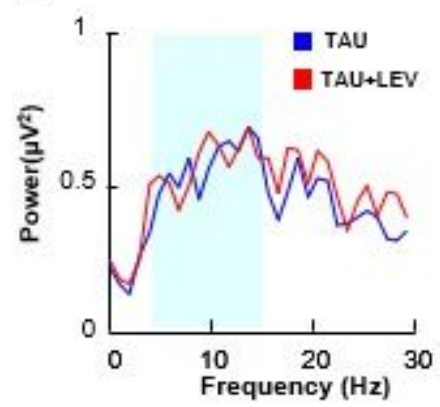

$\mathrm{C}$

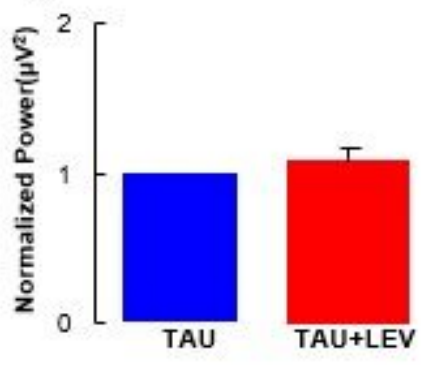

Figure 3

Taurine mediates LEV-induced theta oscillations in the hippocampal CA3 area. A, Time-effect curve for the area power of the oscillations in the application of $100 \mu \mathrm{M}$ taurine, followed by $100 \mu \mathrm{M}$ LEV. $\mathrm{B}$, The corresponding power spectra of of the oscillations shown in A. C, Bar graph summarized the changes in normalized area power of oscillations for $100 \mu \mathrm{M}$ taurine and taurine+100 $\mu \mathrm{M} \operatorname{LEV}(n=6)$. Error bars indicate SEM. * indicates $\mathrm{P}<0.05$, ** indicates $\mathrm{P}<0.01$, in comparison with antagonist, paired t-test.

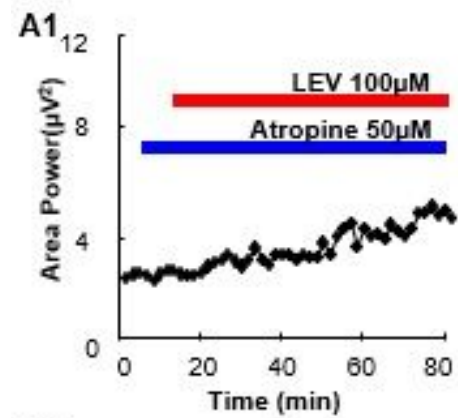

B1

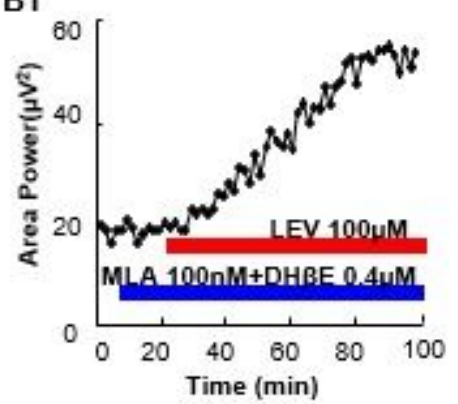

C1

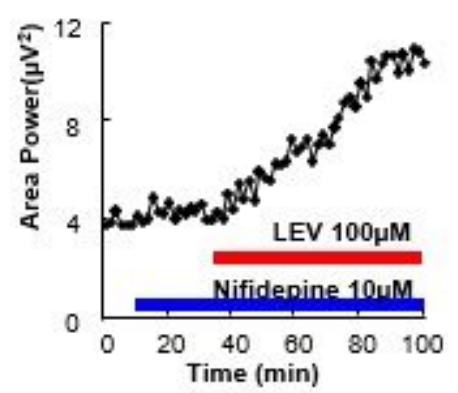

A2

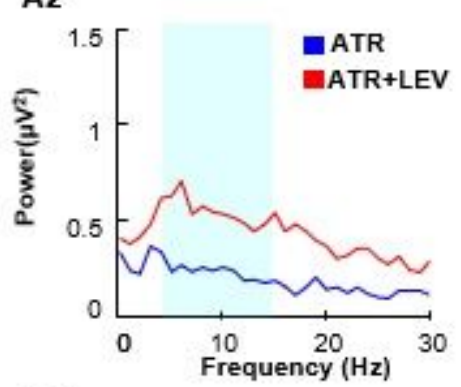

B2

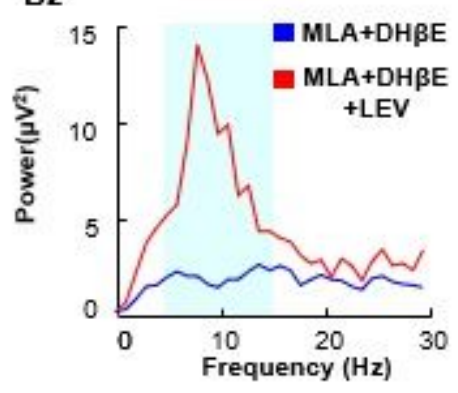

C2

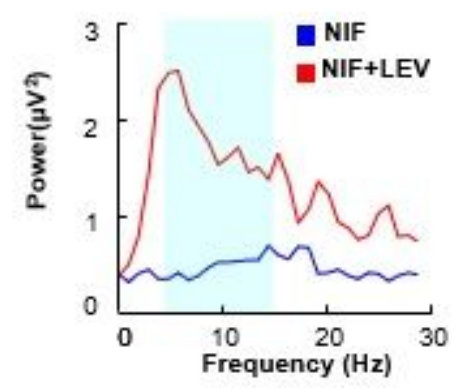

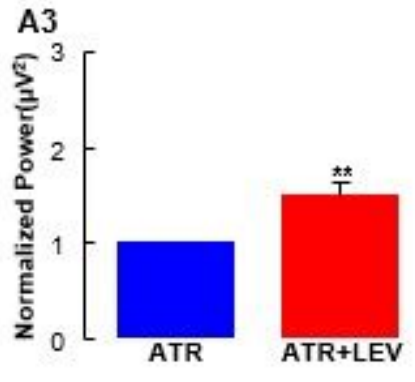

B3

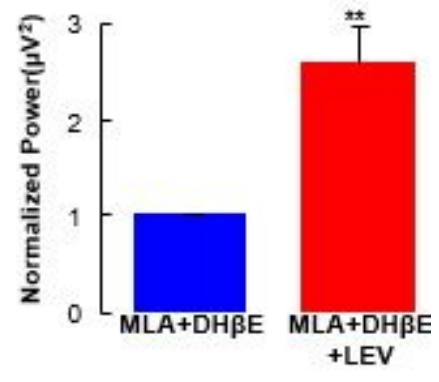

C3

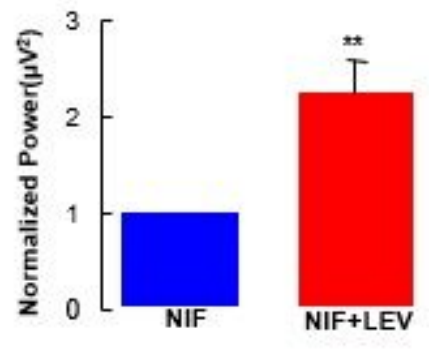

Figure 4 
mACh receptors but not $n A C h$ receptors or L-type Ca2+ channel mediate LEV-induced theta oscillations in the hippocampal CA3 area. A1, Time-effect curve for the area power of the oscillations in the application of $50 \mu \mathrm{M}$ atropine, followed by $100 \mu \mathrm{M}$ LEV. A2, The corresponding power spectra of of the oscillations shown in A1. A3, Bar graph summarized the changes in normalized area power of oscillations for $50 \mu \mathrm{M}$ atropine and atropine+100 $\mu \mathrm{M}$ LEV $(n=10)$. B1, Time-effect curve for the area power of the oscillations in the application of $100 \mathrm{nM}$ MLA and $0.4 \mu \mathrm{M}$ DHßE, followed by $100 \mu \mathrm{M}$ LEV. B2, The corresponding power spectra of of the oscillations shown in B1. B3, Bar graph summarized the changes in normalized area

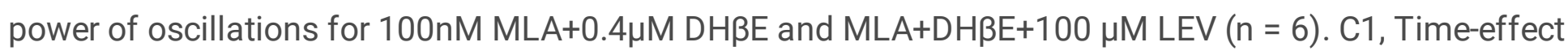
curve for the area power of the oscillations in the application of $10 \mu \mathrm{M}$ nifidepine, followed by $100 \mu \mathrm{M}$ LEV. C2, The corresponding power spectra of of the oscillations shown in C1. C3, Bar graph summarized the changes in normalized area power of oscillations for $10 \mu \mathrm{M}$ nifidepine and nifidepine $+100 \mu \mathrm{M} \mathrm{LEV}$ ( $n$ = 6). Error bars indicate SEM. * indicates $P<0.05$, ** indicates $P<0.01$, in comparison with antagonist, paired t-test.

\section{Supplementary Files}

This is a list of supplementary files associated with this preprint. Click to download.

- supplement1.pdf 